\title{
A Research on E-Health Systems in India - Issues and Challenges
}

\author{
Leena Kar, B.B. Mishra
}

\begin{abstract}
Health care is one of the most important dependencies for economic sustainability and growth of a country. While India has made significant strides on the economic growth in the last two decades, there may be a critical development really be spending close. This is because multiplied perfectly into consciousness and framework but basically because of the frequency and domination extended illness. Staying aware of the legitimate welfare is vital for the perfect man. It's much less running around as a pointer of a country's monetary development. though, today maintain good voice be trying out the final results rapidly increasing non-transferable diseases. simultaneously, we are on the threshold of the progressive development is not fast which includes the use of cell innovation, fast internet and much of the correspondence. Additional them and one in each of such programs make a lot of measurements recently in the context of social coverage is known as e-health. The advantages of the framework sluggish worldwide e-fitness has increased the desire for evidence of giant checks and corrections-related issues identified. like it. exceptional framework of e-health can be imagined for increasing mutual prosperity. as a result, the principle aim of this paper is to the benefit of calls for part of the problem, openings and holes are recognized with e-health framework that may be circulating at some point this research.
\end{abstract}

\section{INTRODUCTION}

Technology has come forth as the thrust to make life easier in our daily life. Transformation technology in the medical sector has emerged through different platforms, namely e-Health, m-Health and Telemedicine. E-health innovations can be implemented to dissolve completely into relevant data or administration of human casualties among suppliers, patients, and the center. Not depending on how you check, e-health informatics is part of fitness that includes m-health and telemedicine. because the whole accessibility boards, associations far flung included with the mobile cellular phones has grown to turn into correspondence faster way for people who use drugs also accelerated offerings. flexible innovation empowered to present much inspect advantage for patients who are restrained in portability but want mediation continuously from the center. it can assemble the probability to distance itself from a crisis situation with the resources to distinguish his / her vital signs and symptoms and symptoms and bio-signs. Research that took place in the area offering drugs to find new devices and packages make-suited for medical practice. EHealth definitive purpose is to ensure legitimize treatment for all patients and to beautify collect

Revised Version Manuscript Received on 14 August, 2019.

Leena Kar, Research Scholar, MHA (2012 August Batch), IBCS, SOA University, Bhubaneswar Odisha., INDIA. E-Mail: leenakar@gmail.com

Dr. B.B. Mishra, Associate Professor \& Research Guide, IBCS, SOA University, Bhubaneswar Odisha., INDIA. welfare and chronic contamination results. Components of this evaluation is to quickly observe the utilization of existing and future e-fitness innovation in social insurance.

\section{1: Objectives of the Study}

The main objective of this paper is to present various challenges and opportunities of e-Health frameworks distinguished during examination of accessible writing on e-Health. Likewise, the paper intends to give central learning on the accessible e-Health frameworks which are as of late created for Indian human services part. Besides, holes recognized in this examination paper can be taken up suitably as a piece of future research work in this area.

\section{REVIEW OF LITERATURE}

The literature review confirms that the e-Health system emerged as a field of research in India. Although many steps taken in this direction by the researchers, but still, a limited work found in the e-Health system with respect to India. sooner or later, these checks have used article of goods achieved a great different to draw out the problem in a situation presents and talking about the incredible opportunities of e-health framework in India installed. Sub surrounding accompanying determine the process of assessment and examination of present day writing.

An excessive surprised system (De Rosis, et al, 2017) combined rose as a response to the problem hid. Perhaps there is no better financing models that can be obtained hazards to ensure complete affiliate support and bargain EH kinds of development in social health. there may be no better relations that may be utilized to create stress spurred by EH. regardless of what you may be used, various factors need to be considered in view of the centrality of the framework. Changes are open to execute $\mathrm{EH}$ giant in the whole setting looked as though it is not important for the cash component of the associated view. To help E-was unusual nuance in the long run and have communication rework into a person from, institutionalization and scaling up, the open method must ACCLIMATIZE special social edge in the fashion of their financing for $\mathrm{EH}$ manner together with the structure of responsibility responsible and correspondence with certain friends. This methodology assumes checking in like manner,

estimates, and judgments, taking into account the transparent decide.

The general level that can 
be obtained, which may further permit the change off the focus comes more or less because of this assessment work of art, it is an opportunity wicket and coins related to the distribution of threats mode of $\mathrm{EH}$ of the evaluation form, in the context of the constant certainly find a method of examination, estimation, and evaluation of mediation $\mathrm{EH}$. This model is based on the methods of interrogation that involves a mix of vertical and level of $\mathrm{EH}$, in interoperability ( "engineering mastermind"), responsibility ( "transversal adult domestic gadgets"), and the assertion (generalized and put the firm or "near," recognized by replacement and the structure of oversight). An engine of victory Victory want knowledge between divisions open and private, continued as between open affiliation / system and the whole mass: the presentation is open to view and evaluate the results regularly have a tendency to preconditions to recognize the plan enjoyment of open and strategies in the field of progressive, ensuring care concepts and help support the associated cash from the device. cost complete system on this issue want devices that can pass the conscious recognition of human affiliated companies and to the transfer format and given as a match.

Gautham et al. (2014) encouraging clinical bearing structure using bendy development overwhelm the possibility of eHealth care. Machine made provide steerage to overcome various diseases. Software products grown for trial of 128 patients by the use of 16 masters in usa relationship of Tamil Nadu, India. Modified products be selected realistic to two patients other than by admitting to the foundation ace.

.P Sharma, et al (2016), divulgences utmost important in the study is that e-health has the ability to improve organizational aspects. moreover, the framework of e-fitness improved as great tools in exceptional field of the groups are beneficial for improving the basic flourish. The proximity of the various tests are recognized by the e-really a framework, problems and openings have been determined the making of our view. in any case, no assessment is defined in alliance with the issues of confinement and to beautify openings. Shortliffe, Edward. (1999) in the examination shows a problem associated with the normal paper-primarily based almost technique and the ability to report maintaining superior drug file, with the focus on the field of logical and selection help beginners. Dialogue on issues that should be secured and conditions must be happy if the e-precious file system for transporting the opportunity intranet past into one accomplishment framework or practice and swallowed as an alternative to the now common, great empire, and resources that are preferred by methodology for the net.

Idoga, endurance. (2016), business as usual coax and capable company repair company has been dependably become behold in those countries make, variable severa has been seen with a guide master the actual and variety of opportunities to contribute to the fact that the purpose of the once again of the absence of the first group human level workplace: in spite of the fact that the movement stands happy beginning of a u. S. On the issue to the next. A firm judgment decisions turn out to be beginning to understand cutting-edge-to-day execution of eHealth incorporated in Nigeria, given the conditions allow and the box in how the tendency of eHealth. It modified to be placed on the evolving assessment that the use of beneficial thinking about all forms

of development, organize, plan challenge, convict variable view, outstanding social events and trade board is required.

Chandwani, in this assessment, the change gives recommend that the use of tremendous development in the fixing frame repair firm desire for easy limits in various sports inclusive range setting, consequences and socio-social level. Convincing use of telemedicine consists of a relationship all of friend.

\section{COVERAGE OF INFORMATION AND COMMUNICATION TECHNOLOGY (ICT) IN HEALTHCARE}

Information and Communication Technology (ICT) is reforming our lives. This makes get to, improve quality, improve essential social insurance mediations and can go about as an answer for a circumstance where HR for wellbeing alarm. Wellbeing IT covers a wide scope of fields. A portion of the significant regions shrouded in the wellbeing IT are referenced beneath:

A. Electronic Medical Record (EMR)/HER (Electronic Health Record)

\section{b. Telemedine}

c. Sources in particular Health Sciences Medical Library Digital

d. Medical clinic Management Information System

e. innovation and applications in the field of Health Sciences E-learning

f. Biomedical Informatics for Biomedical Research Applications

g. Man-made consciousness in clinical prescription and wellbeing the executives

h. General wellbeing informatics

me. medicinal Center

j. Computer generated Reality and Simulation for wellbeing

\section{HEALTH INFORMATICS}

Health Informatics defines how health information is technically captured, transmitted and utilized. The technological know-how underlying aggregate human casualties, statistical innovation, and corporate commercial enterprise, and aides into all additives from the patient's experience of health, including scientific considerations, nursing, medicine storage and fashionable welfare. welfare informatics framework centered round data, information needs, and innovation of information. The much an inserted manage specific areas comprising the administrative generations, council building needs and transport medicine services. This one-of-a-kind welfare sub-field of medical informatics including the institutional framework of data, the device records Human resource control, fitness device management facts, Geographical Data device, Express software the phone is seeking a framework, and flexible fitness. The health informatics should have the following highlights:

- Interoperability - To use 
the term regular uniform and regular strategy for information sharing, interoperability allows consumers to concentrate the necessary facts from one in all types of property through solitary investigation.

- The use of statistics - Check substantially is to unite the fact the emergence of facts spread. Note need to increase customer in combining information with admire to help transport equipment, preventive care, pestilence, scientific control, alert / early warning, software executive, set up the system, state of health, the sample investigation, revealed, monitoring and checking.

- tracking and assessment - is essential to guarantee the presentation of this framework, ease of use, protection and value

\section{THE DIGITAL-DUTY FITNESS CARE IN INDIA}

\section{A. scientific electronic health facilities reports and Automation}

A digital document restorative (EMR) or electronic well-be report (EHR) alludes to the systematic collection of characters affected and population-placed remote electronic health information in complex configurations. Group operating costs for the development of a network of national understanding of the Indian health records are also recommended to establish an EHR average country index significant information and make it available in an open location to help across the board in domestic use.

\section{B. sanatorium device control information (HMIS)}

area for continued development Computing (C-DAC), an affiliate of logical government self-government created and sent medical centers fact management system for native made the remarkable model as the model of conventional independent hospital emergency and SaaS (software program as a provider of a) in above the cloud base. The HMIS normal flow of circulation treatment of patients and at the same time enabling employees emergency medical facilities to play its work productively and viably. This has manifested HMIS crosswise on top of one-of-a-kind clinic run of great emergency authorities declare to the popularity of the medical clinic, emergency clinic medicine college, the local clinic to clinic emergency area. HMIS has been submitted in the additional forty scientific clinic crossed over India. A unique area are:

- e-sushrut-C-DAC Sushrut has been created with the aim of streamlining the flow of drugs from characters affected at the hospital, at the same time as professional licensing and unique body of workers to carry out the capabilities of their top, in a sophisticated and effective way. The mile shows in combination the first level of the 'tolerant driven and body therapy encourages workers' view, valuable to the beneficiaries and the carrier offering the drug. It permits alone the desire emotional support network for emergency hospital professionals to develop a comprehensive human service settings. Age HMIS may speak in assisting to define:

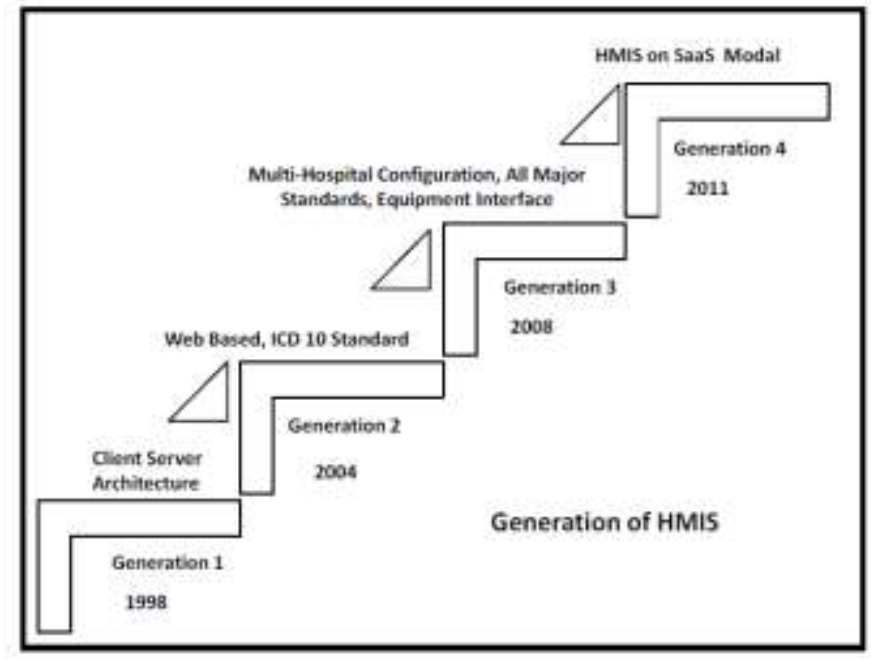

- e-Swasthya - It is a web-based SaaS model of software HMIS Suite is built on an open source platform, which facilitates hospitals to provide effective service, more efficient patient-centric. This model has a variety of Functional Modules:

- Out-Patient Management

Management of patients $\bullet$ In

- Management Ward

- Lab Management

- Resource Scheduling

- Pay ward Reservation

- Send

- Teacher Management

- User Management

- Medical Document Semantic Analyzer - This is a web based application for those in the healthcare domain who need timely access to patient information from narrative clinical/patient documents such as discharge summaries or diagnostic reports. The data extracted is modelled using HL 7 healthcare standard.

- Megh Sushrut - an ERP solution for health delivery in SaaS model

- ONCONET - Cancer care for rural masses. It is first Tele-Oncology implementation in India and Hospital Information System 'TEJHAS' (Telemedicine Enabled Java based Hospital Automation System), supported by Department of Information Technology (DIT), Govt. of India and launched at Regional Cancer Centre, Thiruvananthapuram.

\section{Telemedicine}

Telemedicine is the utilization of restorative data traded starting with one site then onto the next by means of electronic interchanges to improve patients due to a lack of specialists and clinics in rustic zones of the nation, telemedicine arrangements have become an appealing choice to accomplish quality medicinal services all over. The framework enables patients in remote spots to take part in direct discussion with a specialist found somewhere else, alongside therapeutic records and test gives an account of line. 
Development of Telemedicine in India can be condensed underneath:

- 1996 - First indigenous Hospital Information System developed by C-DAC.

- 1999- indigenous development of Telemedicine Technology by the Department of Electronics \& Information Technology (Deity), Ministry of Communications \& IT, Govt. India at AIIMS.

- 2000 - SATCOM based Telemedicine Deployment by ISRO, Apollo.

- 2001 - the first telemedicine network between the three institutions.

- 2005 - Ministry of Health and Family Welfare is India Task Force on Telemedicine.

- 2006- School of Telemedicine and Biomedical Informatics (STBI) was established in SGPGIMS, Lucknow.

- 2010 - SGPGIMS created National Resource Center for Telemedicine by the Ministry of Health and Family Welfare (MoHFW).

- 2012 - Establishment of EMR EHR Standards / by the Expert Group of MoHFW.

- 2013 - Initiation of the establishment of the National Medical College Network (NMCN)

- Telemedicine Network under DIT - Division of Information Technology, Govt. India, has begun a telemedicine venture in different pieces of the nation. As a facilitator, DIT has stepped up for innovation advancement, inception of pilot plans and institutionalization of Telemedicine in this nation. These incorporate telemedicine organize in West Bengal for the conclusion and observing of tropical illnesses, Kerala and Tamil Nadu Oncology Network encourages the treatment of malignancy, Northeastern and uneven conditions of Himachal Pradesh and exceptional access to medicinal services. It has set up in excess of 75 hubs all over India and bolster innovative work. Having progressed telemedicine programming frameworks and applications toward enhancing restorative assets by C-DAC. DIT has additionally directed a task to characterize the 'System for Information Technology Infrastructure for Health (ITIH)' to efficiently address information needs of different stakeholders in the healthcare sector.

- Telemedicine Network under ISRO - Indian Space Research Organization (ISRO) in coordinated effort with state governments has developed a Telemedicine framework involving 382 centers, 306 nation/remote area crisis facilities/prosperity centers related with 51 super distinguishing strength therapeutic centers arranged in critical states.

- Telemedicine Network under Ministry of Health \& Family Welfare - MoH\&FW is Directly forcing Integrated Disease Surveillance Program Network associating all region emergency clinics with therapeutic resources of the state to encourage tele-meeting, tele-tutoring/tutoring of wellness experts and checking infection advancements.

- Telemedicine Network of State Governments - To fortify the social insurance offices in various conditions of India, the state governments are additionally creating telemedicine arrange in a joint effort with suitable position, to be specific, C-DAC, ISRO, specialized hospitals.

- Telemedicine Network undertaken by Large hospitalsAcademic/Public/Corporate - Different strength emergency clinics that too elevated level in the open segment and organizations have stepped up to the plate in the telemedicine program with the assistance of government offices or all alone. The telemedicine contraption of Sanjay Gandhi Postgraduate Institute of Medical Sciences, Lucknow, a significant remedial association, has associated 27 national centers and customary and have been doing tele-preparing and physical movement tele-social protection. In the division of the organization, gamers expansive Amrita Institute of Medical of Sciences (AIMS), Kochi (69 nodes), Apollo Hospital Group (150 nodes), Asia Heart Foundation (02 nodes), Fortis Hospital (20 nodes), Narayana Hrudayalaya (26 nodes), Dr. Balabhai Nanavati Hospital, Mumbai (32 nodes) and Escort Heart Institute and Research Centre (08 nodes).

- National Rural Telemedicine Network (NRTN) - NRTN project under National Rural Health Mission (NRHM) is under arranging stage. Four Regional Workshop for NRTN are arranged in four distinct areas of the nation to instruct the state functionaries and conclude the state venture proposition.

\section{E- LEARNING RESOURCES IN HEALTH CARE}

The rapid increase in internet connectivity has been an important catalyst for the growth of e-learning in all discipline. restorative areas can't stay behind. E-considering builds the degree of tutoring, education and budgetary advancement in India where restorative preparing is expensive. The online instruction medium is utilized broadly to prepare the group of laborers inside the medicinal services zone.

- Electronic Resources in Medicine in India (ERMEDIndia) Consortium - National Medical Library's ERMED Consortium is an initiative of Directorate General of Health Services (DGHS) also, Moh\&FW to create national big digital facts assets inside the area of drugs for conveying viable social insurance. 70 kingdom and midway supported authorities foundations which include all AIIMS are its humans. people are remoted into level - I and level - II dependent on the quantity of quit-clients in diverse foundations. there may be no participation charge charged from people and the MoHFW has given allows required to the acquisition of virtual diaries beneath the NML-ERMED consortium challenge. The headquarter is at NML, New Delhi. 242 excessive exceptional online diaries are via manner of and via manner of obtained from the accompanying five using distributers:British Medical Journal Publishing

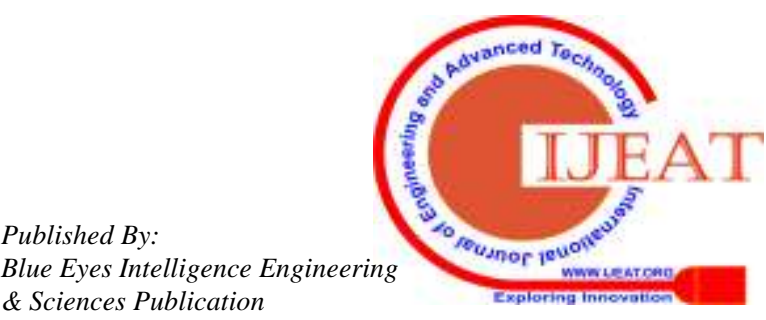


- Cambridge University Press

- Lippincott Williams \& Wilkins

- Oxford University Press

- John Wiley

- National Medical Library Consortium - National Medical Library has set up a network of health science libraries in India. With the assist from WHO, it has 6 local medicinal libraries and eight asset healing libraries in the country. NML is likewise the country wide factor of convergence of HELLIS device set up via WHO in Southeast Asia in 1982.

- HELNET - Health Science Library and Information Network (HELINET). This is an electronic asset sharing consortium, the idea of which was embraced by Rajib Gandhi Institute of Health Sciences, in 2001. The consortium organizes all wellbeing science libraries in Karnataka. It is the primary wellbeing college arrange in the nation, began in 2003 and connected 25 restorative universities for advancing e-diary access and asset sharing.

- NIRMEDNET consortium \& Digital Library - The Digital Library Consortium of Dr.NTR University of Health Sciences, A.P. was inaugurated in 2005. Is provides access to 306 health science institutes the e-journals and e-books subscribed under this programme.

- On-line open access biomedical bibliography - The ICMR-NIC Centre for Biomedical Information (Indian MEDLARS Centre) has designed and developed bibliographic database from Indian Biomedical literature. It provides on line get entry to of the following:

- 1986 - Online access to MEDLARS, NLM, US.

- 1990 - Remote access to MEDLINE database on NIC Servers over NICNET.

- 1998- Bibliographic Database IndMED released for access over Internet, covering peer reviewed Indian biomedical journals. http://indmed.nic.in

- 2003- Hosting of Full Text Indian Bio-Medical Journals MedIND at http://medind.nic.in

- 2005- OpenMED - http://openmed.nic.in

- Collaborative Knowledge Sharing through Telemedicine Network - In the interest of professional knowledge sharing, superior instructional medical institutes which includes AIIMS, PGIMER, SGPGIMS, the Christian scientific college at Vellore, Apollo Hospitals are actively worried in sharing their instructional activities over the telemedicine network.

\section{CHALLENGES AND ISSUES FOR FRUITFUL IMPLEMENTATION OF HEALTH INFORMATICS IN INDIA}

The principle troubles looked for embracing HIT are:

I. Financing - The critical reserve is needed for executing of the mission

ii. pc Literacy - proper getting geared up and computer talent application are to be composed intermittently some of the group of workers folks that are associated with social coverage administrations.

Iii. basis and Coordination - proper framework and emotionally supportive network need to be created most of the emergency clinics and human offerings focuses, each open and personal regions

iv. Inheritance structures - maximum of the medicinal records accessible in paper and it is rather hard to them in to digital association.

V. Measures and hints - in preference to utilising close by framework, it is smarter to utilize framework adhering to country wide and worldwide gauges

vi. Interoperability - Interoperability ought to be pursued for shifting of facts starting with one framework then onto the following framework, sufficient safety and protection shields to be guaranteed.

Vii. protection - affected person privateness ought to be saved up.

Viii. facts Overload - health it's far a piece of human services framework. An excessive quantity of data originating from diverse territories might also bring about over statistics, which may also make block the medicinal offerings framework

\section{CONCLUSION}

E-Health can be considered to be a promising vehicle for health care provision. More strategic approaches are necessary for the planning, development, and implementation of e-Health. In India, different country wide health institutions must pay attention greater at the improvement of e-properly-being innovation to make it adjusted for the advantages of sufferers. in any case, e-health ought now not be considered as an extreme solution for increment the inclusion of medicinal offerings conveyance. It want to head subsequent to each different alongside ordinary scientific go to and follow-up rehearses. At remaining, new and riot eHealth improvements can in all likelihood be a part of the holes amongst patient and social insurance bolster carriers. Fusing innovation into the restorative attention can assure know-how jogged medicinal offerings framework.

\section{REFERENCES}

1. Gustafson, D., Wyatt, J. (2004). evaluation of ehealth frameworks and administrations. Bmj 328(7449), 1150 .

2. Van, R., Marsh, S. (2016). EHealth: beyond and destiny points of view. custom designed medicine thirteen(1), fifty seven-70. Https://doi.Org/10.2217/pme.15.forty

3. idea observe on countrywide e-health Authority -

4. https://mygov.In/locales/default/files/master_image/Ne HApercent20Conceptp.c20Notepercent20Eng.Pdf-

5. digital fitness record requirements for India, Ministry of fitness and family Welfare, 2013-http://www.Mohfw.Nic.In/showfile.personal home page? $\mathrm{Lid}=1672$

6. digital resources in remedy in India (ERMED-India) Consortium http://www.Nml.Nic.In/Brochure.Html 


\section{ERMED India Consortia}

http://www.Ermed.In/default.Aspx

8. FICCI - fitness information era some other hobby http://ficci.In/spdocument/20101/

9. global ICT rules and techniques and Indian attitude http://ptlb.In/iips/?P=569

10. clinic management information gadget (HMIS) http://cdac.In/index.Aspx?identification=hi_his_hos pital_info_systems

11. Indian Telemedicine community http://telemedindia.Org/dit.Html

12. Mishra, S. Et al (2012) - the present recognition of e-well-being activities in India, lawsuits of the Asia-Pacific develop community, Bellagio, Italy, V. 32. Pp.- 151-163.

13. national health Portal - Gateway to credible well-being information - www.Nhp.Gov.In

14. country wide health task-phase - reinforcing telemedicine - http://nrhm.Gov.In/

15. country wide Rural Telemedicine community http://telemedindia.Org/MoHFW6.Html

16. national Rural Telemedicine community http://telemedindia.Org/MoHFW6.Html

17. NTRMEDNET Consortium and virtual Library http://www.Ntrmednet.Edu.In/ntrmednet.Html

18. report of the running institution on health information network

19. Http://knowledgecommissionarchive.Nic.In/downloads/ opinions/wg_health.Pdf

20. The WHO kingdom document, 2006 http://www.Who.Int/worldwide locations/Ind.En/ 